\title{
EL CONOCIMIENTO DE LA HISTORIA DE LA UROLOGÍA: UN COMPROMISO DOCENTE
}

\author{
E. MAGANTO PAVÓN \\ Servicio de Urología. Hospital Ramón y Cajal. Madrid.
}

Actas Urol Esp. 28 (10): 711-713, 2004

$\mathrm{S}_{\mathrm{s}}^{\mathrm{e}}$ cumplen ahora ocho años desde que la Junta Directiva de la Asociación Española de Urología adoptara la brillante decisión de crear, dentro de la Sociedad, un grupo que se encargara de todos los aspectos inherentes a la historia de la especialidad en nuestro país: la Oficina de Historia.

El grupo, que se fundó por una propuesta del que redacta este artículo, en ese momento miembro activo del Historical Committee de la Asociación Europea de Urología y de la Sociedad Española de Historia de la Medicina, nacía con la clara vocación de suscitar entre los miembros de la Asociación un movimiento que estimulara la afición al estudio e investigación en el campo de la Historia de la Urología. El fin último de este movimiento sería confeccionar entre todos los urólogos interesados una definitiva Historia Biográfica y Bibliográfica de la Urología Española que por esas fechas estaba aún por hacer.

Aunque entre las principales misiones de la Oficina estaban las de divulgación histórica y el asesoramiento de la Junta en temas de esa índole, el grupo se fijó una serie de objetivos para los siguientes diez años a semejanza de los que el Comité Histórico de la Asociación Europea de Urología había asumido cuando fue creado unos años antes.

Fueron estas directrices del Historical Committee $^{1}$, pero con sus peculiaridades, las que han guiado a los miembros de muchos comités y grupos históricos europeos y a los de nuestra Oficina durante estos años. Como europeos los integrantes de estos grupos deberían cooperar en el conocimiento de la historia de la especialidad conjuntamente si bien cada país tendría su singularidad. Entre estas labores divulgativas estarían: el estudio de la evolución y desarrollo que la especialidad había sufrido a lo largo de las épocas, reescribir la historia de la urología de cada país pero dentro del contexto europeo, y reeditar y sacar a la luz antiguos textos considerados cumbre de la urología universal para que fueran conocidos en el resto de los países.

Como era de prever tan ambiciosos proyectos no se podrían llevar a cabo sin el empuje, compromiso y espíritu cooperativo de todos los miembros del Historical Committee, sin el asesoramiento de traductores y expertos en Historia de la Medicina, y sin un medio de difusión en inglés que sirviera como vehículo divulgador de los trabajos escritos. Todo ello, naturalmente, auspiciado y financiado por la Asociación Europea de Urología.

Aunque la Asociación Europea disponía de la revista "European Urology", órgano de la Sociedad, con un notable factor de impacto y fundada 20 años antes, para estos fines se juzgó oportuno la creación de publicaciones independientes. En 1994 la Asociación Europea de Urología funda "de Historia Urologiae Europaeae”, revista de periodicidad anual, en la que hasta la fecha se han publicado de forma resumida la historia de la urología de todos los países del continente (incluido el nuestro) y un sinfin de trabajos de corte histórico.

En 1996 aparece el primer volumen de la colección "E.A.U. Classical Library", otra publicación periódica que divulga los libros europeos antiguos en edición facsimilar, transcripción diplomática y traducción al inglés del texto original. Por parte española uno de ellos ha sido "Cura de la Piedra y dolor de la yjada o/y cólica renal" (1498), incunable de Julián Gutiérrez de Toledo, publicado en facsimil, castellano moderno e inglés en 2000.

Con estas publicaciones el Historical Committee conseguía cumplir la mayor parte de los objetivos que se propuso en su momento continuando hasta la fecha con su labor divulgativa y de promoción de la historia de la especialidad. 
Todo este extenso preliminar viene al caso para justificar los motivos que en su momento expuse ante la Junta Directiva de la Asociación Española de Urología para la creación de un grupo similar al Historical Committee dentro de nuestra Sociedad. En mi opinión, era necesario promover entre los urólogos españoles la afición por los estudios históricos, estimular a los más interesados para que prosiguieran con sus labores divulgativas y de investigación archivística y documental, e imbuir en las nuevas generaciones de especialistas el cariño por el conocimiento de su pasado. La Oficina de Historia fue la solución a esa necesidad que el Profesor Luis Resel Estévez, presidente en ese momento de la A.E.U., ideó para llenar ese vacío que en otras sociedades urológicas europeas y americanas ya estaba ocupado.

Al igual que sucediera con el Historical Committee, la Oficina de Historia se marcó en su momento una serie de objetivos (concretamente nueve $)^{2}$ que hasta la fecha se han venido cumpliendo, con mayor o menor éxito, gracias al empuje de todos sus componentes.

El principal compromiso de la Oficina, el fin último para el que en su momento fue creada: confeccionar entre todos los urólogos interesados una definitiva Historia de la Urología Española que sirviera como referente a las futuras generaciones, es ya una realidad. La "Historia Biográfica y Bibliográfica de la Urología Española” (2 vols. años 2000 y 2002) ${ }^{3}$, aunque con algunas lagunas y por supuesto mejorable, es el ejemplo vivo y perdurable de que la historia de la urología española ha calado hondo entre los miembros de la Asociación. Más de 20 urólogos españoles, muchos de ellos no miembros de la Oficina, han participado en la confección de los capítulos de la obra y me consta que en muchos de ellos se ha despertado o ha renacido la afición por la historia, pues me lo han confirmado verbalmente y he podido comprobarlo por sus publicaciones posteriores de corte histórico. Y es que la investigación archivística o la revisión documental o bibliográfica de carácter histórico suele ser un acicate para los no iniciados, una especie de catarsis.

Para los ya aficionados, para los que estamos inmersos permanentemente en los estudios históricos, las sensaciones son otras. Aunque la investigación documental exige siempre muchas horas de estancia en archivos y bibliotecas y el precio a pagar -nuestro tiempo libre- es demasiado costoso, al final siempre solemos obtener muchas satisfac- ciones que, como afirmaba el Prof. Albarracín Teulón ${ }^{4}$, no pueden ser explicadas por puro dilettantismo.

Podrá argüirse que quizás esta labor de investigación, la valoración crítica de los textos antiguos y el descubrimiento de nuevas fuentes documentales, corresponde a los historiadores de la Medicina y no a los urólogos. También que a los especialistas solamente nos toca comentar y contrastar dichas obras y descubrimientos con respecto a los de otros países y con el saber urológico actual para darlos a conocer fuera de nuestro entorno. Sin embargo, mi parecer a este respecto es otro. Pienso que los urólogos modestamente y dentro de nuestras posibilidades, podemos y debemos contribuir a la investigación archivística y documental de nuestra especialidad aportando datos inéditos o de carácter local desconocidos para investigadores e historiadores profesionales de la Medicina. El urólogo no debe abandonar esta parcela como tampoco debe perder ninguna otra de la especialidad.

Esta prioridad de los estudios históricos en el campo de la Urología fue bien comprendida desde los inicios de la especialidad por especialistas extranjeros de tanto prestigio como Ernest Desnos (1914), Leonard J.T. Murphy (1972), René Küss y Willy Gregoir (1988) y también por muchos urólogos españoles de renombre. Desde la fundación de la A.E.U., en 1911, la Sociedad siempre tuvo buenos historiadores, y ya hay una larga lista de urólogos aficionados a la historia de la urología, como R. Mollá y Rodrigo; A. Moyá y Prats; A. Pulido Martín; P. Cifuentes Díaz; A. de la Peña Pineda; P. Gausa Rull; J. Montero Gómez; A. Puigvert Gorro; L. Cifuentes Delatte; R. Vela Navarrete; J.L. Insausti Cordón y un largo etc.

Es por eso que las generaciones actuales y las futuras debemos recoger el testigo y continuar la tradición iniciada por nuestros mayores para que la urología española alcance el reconocimiento internacional que le corresponde y que sólo recientemente se ha comenzado a lograr. Abundando en este tema habría que recordar aquí la encomiable labor que, por ej., realizó el Prof. Antonio Puigvert con sus publicaciones históricas sobre la figura de Francisco Díaz y su Tratado de Urología (1978) ${ }^{5-6}$ -olvidados o desconocidos hasta entonces por los urólogos europeos y americanos- y con la creación de la medalla Francisco Díaz en 1972; con ellas el "Padre de la Urología" y su obra alcanzaron por fin el reconocimiento internacional que se merecían. 
Si bien Puigvert utilizó la revista en inglés "European Urology" para lograr mayor difusión internacional de su estudio sobre el cirujano de Felipe II y su Tratado de Urología, el problema del idioma no debería suponer una traba para publicar. Aunque en la actualidad tratemos de que nuestros estudios e investigaciones (históricas o no) se publiquen y sean dadas a conocer en medios escritos de difusión contrastada y con un elevado factor de impacto y esto, aparentemente, sólo sea posible en revistas y publicaciones de habla inglesa, no deberíamos olvidar que en España disponemos de revistas urológicas de ya larga tradición y cierto nivel internacional que últimamente se ha visto incrementado por su aparición "on line". Las posibilidades de difusión internacional a este respecto son inimaginables, asî que cuanto más y de mejor calidad publiquemos en ellas mayor reconocimiento obtendremos de nuestros trabajos. Hasta es posible que en un futuro próximo alcancen el nivel de notoriedad foránea que todos deseamos, ya que los ensayos y trabajos de corte histórico nunca pasan de moda y casi siempre suelen ser leídos por los científicos como descanso intelectual. Por otra parte está demostrado que si los trabajos son de calidad y los estudios están hechos con rigurosidad casi todos ellos servirán de referente para estudios posteriores por lo que, con toda probabilidad, aparecerán citados en la bibliografia.

Parece, y esto no es una simple apreciación mía, que en los últimos diez años el auge de las publicaciones de corte histórico en las dos revistas españolas de más prestigio internacional es incesante. Hasta 1992 se habían publicado un total de 30 artículos de este porte desde la fundación de ambas (1944 Archivos y 1977 Actas). Desde 1993 hasta 2003 se han publicado 50 artículos. Esto sin contar los publicados por urólogos españoles en otras revistas nacionales e internacionales.

En cuanto a libros sobre Historia de la Urología española, se cuentan un total de 7 editados desde 1993 sin reseñar los capítulos de carácter histórico y los facsímiles.

También las comunicaciones y pósters sobre historia a Congresos Nacionales e Internacionales han sufrido un notable incremento. En los últimos cinco años se contabilizan un total de 47 pósters frente a 21 del anterior lustro. Esto significa un $6,4 \%$ de pósters históricos sobre el total de los presentados en el último quinquenio.

En referencia a tesis doctorales sobre temas de historia de la urología se han presentado 4 en los últimos cinco años.
Todo ello parece confirmar que el interés por la historia de la urología entre los urólogos españoles ha alcanzado un nivel que muy pocos hubieran podido predecir y que este sigue en aumento.

Quizás en el éxito de este renovado interés, de esta naciente y pujante afición, la Oficina de Historia haya podido jugar algún papel. Modestamente sus integrantes no debemos vanagloriarnos de ello, ya que las labores divulgativas y de promoción son misiones inherentes a cualquier grupo de trabajo que se precie.

Lo que es evidente es que para continuar en esta línea, para que lo realizado hasta ahora no se pierda, se necesita el concurso de las nuevas generaciones. Es necesario que los urólogos jóvenes $-\mathrm{y}$ los no tan jóvenes- se conciencien e involucren en estas tareas que no deben ser consideradas fútiles o de poco interés dentro de su periodo formativo.

El conocimiento de la historia es un compromiso docente que la Urología española debe tomar en consideración y hacerlo suyo.

Mi forma de pensar sobre este tema quedaba reflejado en otro Editorial publicado hace bien poco ${ }^{7}$ :

"el cabal conocimiento de cualquier rama de la Medicina o Cirugía no debe limitarse solamente al saber científico o técnico de la especialidad sino que el práctico debe indagar en el pasado las raíces que dieron origen al nacimiento de la misma”.

\section{REFERENCIAS}

1. The Historical Committee of the E.A.U. European Urology Today, 1996;6(3): 11.

2. Maganto Pavón E. Presentación de la Oficina de Historia de la A.E.U. Página web de la Asociación Española de Urología. Internet: Http://Www.Aeu.Es/Historia/

3. Historia Biográfica y Bibliográfica de la Urología Española. Madrid 2000. Historia Biográfica y Bibliográfica de la Urología Española en el Siglo XX. Madrid 2002.

4. Albarracín Teulón A. Prólogo, En: E. Maganto Pavón: Vida y Obra de Enrique Suender (1829-1897) (Patriarca y alma de la Urología Española). Madrid 1998;16.

5. Puigvert Gorro A. Comentario nuevo a un libro viejo. Actas Urol Esp 1977;1:231.

6. Puigvert Gorro A. Enfermedades de los riñones, vexiga y carnosidades de la verga By Francisco Díaz. Comments on an old book. Eur Urol 1978;4:232.

7. Maganto Pavón E. Historia de la Urología. Nueva Sección de Archivos Españoles de Urología. Arch Esp Urol 2002;55(1):5-9.

Dr. Emilio Maganto Pavón

Oficina de Historia de la A.E.U.

General Pardiñas, 90. $4^{\circ} \mathrm{C}$

28006 - Madrid

(Trabajo recibido el 4 octubre 2004) 